\title{
A traveling atmospheric disturbance generated by a soil colour change in a high-resolution climate model experiment
}

\author{
Elisavet Proedrou ${ }^{1,2^{*}+}$ and Klemens Hocke $1,2,3+$
}

\begin{abstract}
The climate model CESM-WACCM is used to study the way a soil colour change of the eastern region of the Sahara affects the dynamics of the troposphere. The soil colour is darkened for 5 days. The difference between the perturbed model run and the control model run is used to isolate the soil colour change-induced atmospheric perturbation from random atmospheric waves which are stronger by an order of magnitude or more. The perturbation generates a circular wave radially propagating away from the Sahara on the first day of the simulation. After nine hours, the wave front reaches the convection zone in Brazil where a secondary wave is generated and can be clearly seen until 23:00 UT. The mean wave velocities of the traveling atmospheric disturbances are $\langle\mathrm{v}\rangle=200 \pm 50 \mathrm{~m} / \mathrm{s}$ for the primary wave and $\langle\mathrm{v}\rangle=220 \pm 40 \mathrm{~m} / \mathrm{s}$ for the secondary wave. The mean horizontal wavelengths are $\langle\lambda\rangle=3000 \pm 500 \mathrm{~km}$ for the primary wave and $\langle\lambda\rangle=2600 \pm 600 \mathrm{~km}$ for the secondary wave. The mean wave periods are $\langle p\rangle=4 \pm 1 \mathrm{~h}$ for the primary wave and $\langle p\rangle=3 \pm 1 \mathrm{~h}$ for the secondary wave. Since the perturbed model run diverges from the control run with the passage of time, the attribution of cause and effect becomes difficult after a few days. Analysis of the simulation data of the first day leads to a deeper understanding of global teleconnections, radiative transfer and wave-coupling processes between the surface and the atmospheric layers.
\end{abstract}

Keywords: Small perturbation analysis; Traveling atmospheric disturbance; Secondary wave generation; Land-atmosphere interaction; Surface albedo; Lower troposphere; High-resolution climate model

\section{Background}

In our study we investigate whether a high-resolution global climate model can be used to study the generation, propagation and dissipation of atmospheric waves induced by a soil colour change. We are especially interested to know if a cause-effect study can be performed under realistic atmospheric conditions. The attribution of cause and effects is a fundamental problem of complex systems.

At present two types of numerical models are available for studying the climate processes. The idealized models and the realistic models [1]. Idealized models allow

\footnotetext{
${ }^{*}$ Correspondence: elisavet.proedrou@iap.unibe.ch

${ }^{\dagger}$ Equal contributors

1 Institute of Applied Physics, University of Bern, Sidlerstrasse 5, Bern, Switzerland

${ }^{2}$ Center for Space and Habitability, University of Bern, Bern, Switzerland

Full list of author information is available at the end of the article
}

us to conduct detailed studies and hence increase our understanding of simplified or isolated processes. Due to their simplicity these models neglect the role of more complex interactions and hence do not provide a holistic view of the climate system. Realistic models on the other hand, consider almost all processes of the climate system and provide high-resolution climate data, which are rather close to the observations. As a result realistic model data are almost as difficult to understand as the observations. Therefore the recognition of the relevant climate processes, the attribution of climate forcing and their effect on the climate requires advanced methods of data analysis and interpretation (e.g [2-4]).

The generation, propagation and dissipation of atmospheric waves are often studied by means of idealized model simulations. Nicholls \& Pielke [5] conducted such a study using an idealised three-dimensional, fully compressible atmospheric model. Their goal was

\section{Springer}

C 2014 Proedrou and Hocke; licensee Springer. This is an Open Access article distributed under the terms of the Creative Commons Attribution License (http://creativecommons.org/licenses/by/4.0), which permits unrestricted use, distribution, and reproduction in any medium, provided the original work is properly credited. 
to investigate the properties of the atmospheric waves induced by a tropical thunderstorm. Their study showed that the thunderstorm generated not only atmospheric gravity waves, but also thermal compression waves. Gardner \& Schunk [6] used a high-resolution global thermosphere-ionosphere model to examine the effect a large scale perturbation (in this case a pulsating geomagnetic storm) has on the atmosphere. They concluded that this type of storm generates multiple Traveling Atmospheric Disturbances (TADs) coincidently travelling from the northern and southern auroral zone towards the equator and into the conjugate hemisphere.

Atmospheric disturbances are also induced by albedo changes, which can be due to changes in the type of the vegetation, the soil colour, the formation of clouds and other causes. Surface albedo itself can include snow cover, surface water and vegetation change too. Only in the case of a desert like the Sahara, surface albedo might be mainly governed by the soil color. Seitz [7] gives a brief survey about the influences of albedo changes on the Earth's radiation energy balance. According to Seitz [7], the effects of regional albedo changes on the climate system are still not well observed, simulated and understood. Past regional albedo change studies have focused on the effects on long-term climate change $[3,4,8,9]$ and how it can be utilized in geoengineering projects to combat global warming [10]. To our knowledge, there is only one study, which attributed a sudden snow cover in Eurasia to a polar vortex change [3].

Our study is the first to extract and discuss the tropospheric waves induced by a regional soil colour change using a realistic high-resolution 3-D climate model. In the simulation, we change the soil colour of a desert region since this change can be safely implemented in the complex climate model which we use. Furthermore, this simple scenario will allow a clear interpretation of the simulation results.

In the present study, we concentrate on the effects the soil colour change has on the lower troposphere. The generated atmospheric perturbation has a small amplitude so that a small-scale perturbation analysis can be applied to the first 1-2 days of the model simulation. This allows us to study the global propagation of the TADs through the lower troposphere in detail.

\section{Model description}

The Community Earth System Model (CESM) version 1.04 was used to perform our simulation. It is composed of a coupler (CPL) and five fully coupled geophysical models: atmosphere (ATM), land (LND), ocean (OCN), sea-ice (ICE), land-ice (GLC). The models can be set as fully prognostic, data, or stub and are "state-of-the-art climate prediction and analysis tools" [11] when set in prognostic mode.
The ATM in our simulation is the Whole Atmosphere Community Climate Model (WACCM) version 5 [12]. WACCM is often used for the simulation of circulation, thermal tides, gravity waves, wave-mean flow interaction, and atmospheric composition changes in the middle atmosphere [13-20].

It has a fully compressible horizontal discretization, and a quasi-Lagrangian vertical discretization approximation, which ignores the acceleration term in the vertical component of the momentum equation. This approximation is good for scales greater than $10 \mathrm{~km} \mathrm{[12].} \mathrm{It} \mathrm{has} 66$ vertical levels from the ground up to $5 \cdot 10^{-6} \mathrm{hPa}(2.5-149 \mathrm{~km})$. The vertical coordinate is purely isobaric above $100 \mathrm{hPa}$, but is terrain following below that level. The model top is $\sim 150 \mathrm{~km}$. The vertical resolution is $1.1 \mathrm{~km}$ in the troposphere, $1.1-1.4 \mathrm{~km}$ in the lower stratosphere, $1.75 \mathrm{~km}$ at the stratopause and $3.5 \mathrm{~km}$ above $65 \mathrm{~km}$. The horizontal resolution of our simulation is $4^{\circ} \times 5^{\circ}$ (latitude $\times$ longitude), with 72 longitude and 46 latitude grid points. The coupler timestep is $\Delta t=30$ minutes while the time step for the dynamics equations is $\Delta \tau=\Delta t / 8$ [12].

The smallest wavelength that our model experiment can resolve by the finite differencing (that is used by default in WACCM) is twice that of the grid size [21]. Therefore the resolvable waves in the equatorial troposphere have a horizontal wavelength of $\lambda_{\text {horizontal }}>1000 \mathrm{~km}$, a vertical wavelength of $\lambda_{\text {vertical }}>2.2 \mathrm{~km}$, a period of $p_{\text {horizontal }}>2 \mathrm{~h}$ and a wave velocity of $v<\Delta x / \Delta \tau=$ $\Delta x /(\Delta t / 8)=500 /(1800 / 8) \approx 2200 \mathrm{~m} / \mathrm{s}$. Thus the simulation can adequately resolve large scale waves [21].

The land model provides the surface albedo, areaaveraged for each atmospheric column, and the upward longwave surface flux, which incorporates the surface emissivity, for input into the radiation scheme. The surface fluxes of momentum, sensible heat, and latent heat serve as the lower flux boundary conditions for the planetary boundary layer parameterization, the vertical diffusion and the gravity wave drag. The atmospheric radiation is calculated using the momentum, sensible heat flux, latent heat flux, land surface albedos and upward longwave radiation. The upward longwave radiation is calculated by taking the difference between the incident and absorbed fluxes. The incident flux values are determined by means of the daily values of the solar radio flux (F10.7) which are provided by the National Oceanic and Atmospheric Administration's (NOAA) Space Environment Center [22].

The land model used was the Community Land Model (CLM), which has atmosphere-surface coupling, surface colour variability, surface albedo calculation, absorption, reflection, and transmittance of solar radiation, absorption and emission of longwave radiation, sensible heat (ground and canopy) latent heat fluxes and heat transfer in soil and snow [23]. The surface albedo calculation 
depends on whether the top surface is a vegetated canopy or bare ground.

In the case of bare ground the surface albedo calculation requires only the soil colour, which varies with the colour class (soil colour index). The term bare ground refers to any surface that is not covered by vegetation and can therefore be a glacier, a lake, a wetland, snow covered soil or bare soil. In the case of our simulation the only parameter that affects the surface albedo of the perturbed east Saharan area is the soil colour, which is determined by the value of the soil colour index of the area.

The CLM soil colour indices are prescribed so that they reproduce the observed Moderate-resolution Imaging Spectroradiometer (MODIS) local solar noon surface albedo values at the CLM grid cell [23]. MODIS is a set of spectroradiometers in orbit on board the Terra and Aqua satellites. They provide measurements of large scale global dynamics (e.g changes in the cloud cover, radiation budget, processes on the oceans, the land and lower atmosphere). They capture data in 36 spectral bands $(0.4 \mu \mathrm{m}-$ $14.4 \mu \mathrm{m})$ at varying spatial resolutions and image the entire Earth every 1 - 2 days [24].

\section{Methods}

\section{Simulation setup}

In the simulation setup we used the perpetual year 2000 component set (F_2000_WACCM) [11]. A component set is the assemble of a particular mix of geophysical models along with geophysical model-specific configurations and namelist settings. In this case it is a set of two fully prognostic, present day, coupled atmosphere and land geophysical models (WACCM,CLM), a prescribed data ocean geophysical model (docn), a prescribed seaice (CICE) geophysical model and no land-ice geophysical model ([11]). With it, we conduct two simulations. In the first one, from now on referred to as control run, all the input parameter fields remain unchanged. In the second one, from now on referred to as perturbed run, the colour of a small region of the east Sahara, that spans $3 \times 3$ pixels (longitude: $10^{\circ}-20^{\circ}$, latitude: $18^{\circ}-26^{\circ}$ ), is darkened from beige (bright sand) to very dark green (the colour of the darkest forests). To avoid a discontinuity in the soil colour map, the soil colour change is gradually performed with a small change of $50 \%$ at the edge of the Sahara array (soil colour index $=15$ ) and a maximal change in the center of the array (soil colour index $=20$ ) as shown in Figure 1. The simulation spans 5 days starting at 0:00 UT on 01/01/2000 and ending at 23:00 UT on 05/01/2000.

\section{Data analysis}

The surface albedo, the surface temperature, the atmospheric pressure and the vertical wind are extracted from the output datasets for the control and the perturbed run. In the present letter, we only show the results obtained for the vertical wind at $2 \mathrm{~km}$ altitude. A comprehensive study of the disturbances in all parameters at all altitudes is planed as a follow-up-study. In addition we have to design advanced algorithms for the analysis of different wave modes. However the initial data analysis presented here already provides many new results.

As a first step the above parameters are interpolated to the altitude of $2 \mathrm{~km}$ from 0:00 UT to 23:00 UT. Then the control run is subtracted from the perturbed run at each timestep. The mean standard deviation $\sigma=2 \cdot 10^{-4} \mathrm{~Pa} / \mathrm{s}$ for the first day at 23:00 UT is taken as reference for the normalization of the vertical wind fluctuations. To calculate it we derive at first the zonal means of $\sigma$ as a function of latitude for 23:00 UT. Then we obtain the global mean of sigma $\sigma$ from the zonal means of sigma $\sigma_{z}$ by calculation of the surface area preserving mean. For recognition of significant atmospheric waves in the global plots, we divide the vertical wind fluctuations $d \Omega$ by $\sigma$. Variations $>2 \sigma$ have a significance (confidence level) of $90 \%$.

\section{Results and discussion}

The change in surface colour resulted in the appearance of fast propagating primary and secondary waves at $2 \mathrm{~km}$ altitude.

\section{Primary perturbation}

As can be seen in Figure 2a, the primary perturbation, appears over the Sahara at 9:00 UT (four hours after sunrise). The surface colour change causes a convective perturbation in the lower troposphere, a buoyancy oscillation that rises and falls as the day progresses (Figure 2). The warm colours in the figure indicate downward air

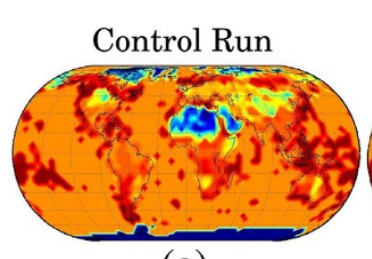

(a)

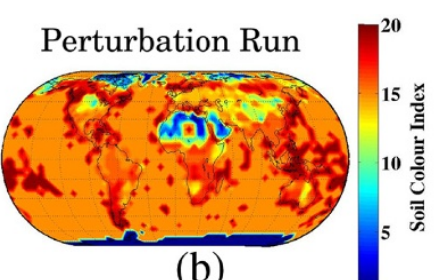

(b)

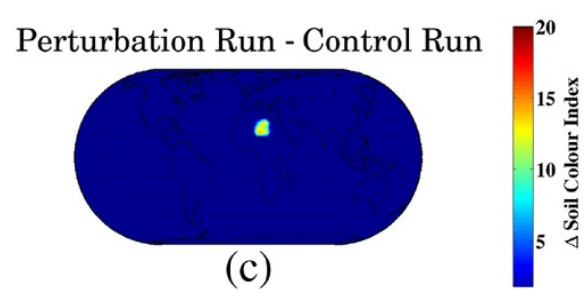

(c)

Figure 1 Simulation setup. (a) soil colour index of the control run, (b) soil colour index of the perturbed run, (c) difference between the soil colour indices of the perturbed and the control run. 


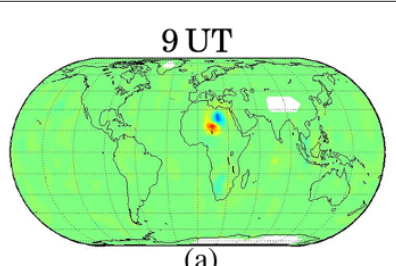

(a)

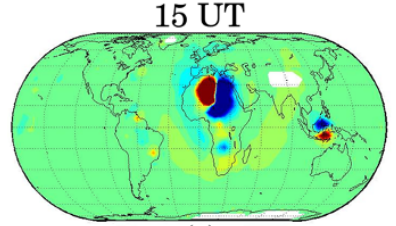

(c)

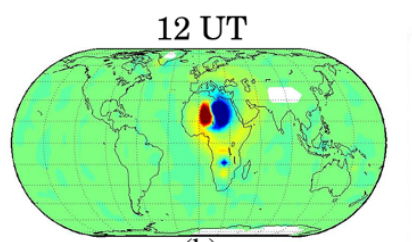

(b)

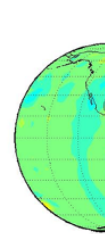

23 UT

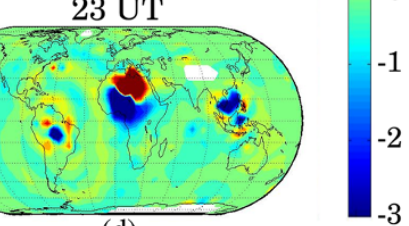

(d)

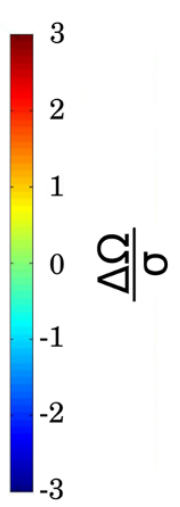
Figure 2 Evolution of the atmospheric perturbation due to the soil colour change in Eastern Sahara during day 1. The difference between
the vertical wind at $2 \mathrm{~km}$ altitude of the perturbed run minus the control run is shown at (a) 9:00 UT, (b) 12:00 UT, (c) 15:00 UT, (d) 23:00 UT. Shades of blue indicate upward motion of the air, while shades of red indicate downward motion. motion and the cold colours indicate upward motion since WACCM provides the vertical wind in $[\mathrm{Pa} / \mathrm{s}]$.

As can be seen in Figure 2b,c,d the perturbation amplitude increases with time to a value of $A>5 \sigma$. We have therefore a $5 \sigma$ confidence $\left(\sigma=2 \cdot 10^{-4} \mathrm{~Pa} / \mathrm{s}\right.$ at this altitude).

Figure $2 \mathrm{~b}$ shows a nearly circular wave ring outgoing from the surface colour change region in the eastern Sahara. The wave ring is also visible in Figure 2c (15:00 UT). The mean horizontal wavelength $\langle\lambda\rangle$ of the wave is calculated as follows:

i. The center of the disturbance is known for the primary wave $\left(22^{\circ} \mathrm{N}, 15^{\circ} \mathrm{E}\right)$. In the case of the secondary wave, its center is determined by an educated guess $\left(10^{\circ} \mathrm{S}, 55^{\circ} \mathrm{W}\right)$.

ii. The positions of the inner and outer ring of the wave ( $R_{\text {inner }}$ and $R_{\text {outer }}$ ) are visible in the global maps of the vertical wind fluctuations at 12:00 UT). Then the ring positions are manually determined, from the center towards the North, East, South and West direction. This gives us four values for the inner and four values for the outer ring.

iii. Then the mean horizontal wavelength is calculated:

$$
\langle\lambda\rangle=\langle\lambda\rangle=2 \cdot\left(<R_{\text {outer }}>-<R_{\text {inner }}>\right) \text {. }
$$

The calculated values for $<R_{\text {inner }}>$ and $<R_{\text {outer }}>$ together with their standard deviations can be seen in Figure 3. The calculated mean horizontal wavelength of the primary wave is $\langle\lambda\rangle=3000 \mathrm{~km}$.

The mean wave speed $v$ is calculated as follows. First the mean horizontal speeds of the inner and outer radii are taken from the inclination of the above mentioned linear regression lines: $v_{\text {inner }}=d R_{\text {inner }} / d t=240 \mathrm{~m} / \mathrm{s}$, $v_{\text {outer }}=d R_{\text {outer }} / d t=170 \mathrm{~m} / \mathrm{s}$. Then the mean of the above calculated horizontal speeds is taken $\langle v\rangle=$ $\left(v_{\text {inner }}+v_{\text {outer }}\right) / 2 \approx 200 \mathrm{~m} / \mathrm{s}$. Its standard deviation is $\sigma_{v}=50 \mathrm{~m} / \mathrm{s}$.

The mean wave period is calculated taking the ratio of the mean horizontal wavelength and the mean horizontal velocity of the wave $\langle p\rangle=\langle\lambda\rangle /\langle v\rangle=4 \mathrm{~h}$. Its uncertainty is calculated using the Gaussian error propagation law $\sigma_{p}=$ $\sqrt{\left(\sigma_{\lambda} /\langle v\rangle\right)^{2}+\left(\langle\lambda\rangle \cdot \sigma_{v} /\langle v\rangle^{2}\right)^{2}}=1 \mathrm{~h}$.

The derived uncertainties mainly reflect the azimuthal variations of the wave parameters. These variations are possibly due to azimuthal changes in the background wind flow, topography, convective activity, Coriolis force and other factors which modulate the radial propagation of the wave rings.

In summary, the soil colour change induced a circular large scale wave with a wave speed close to the speed

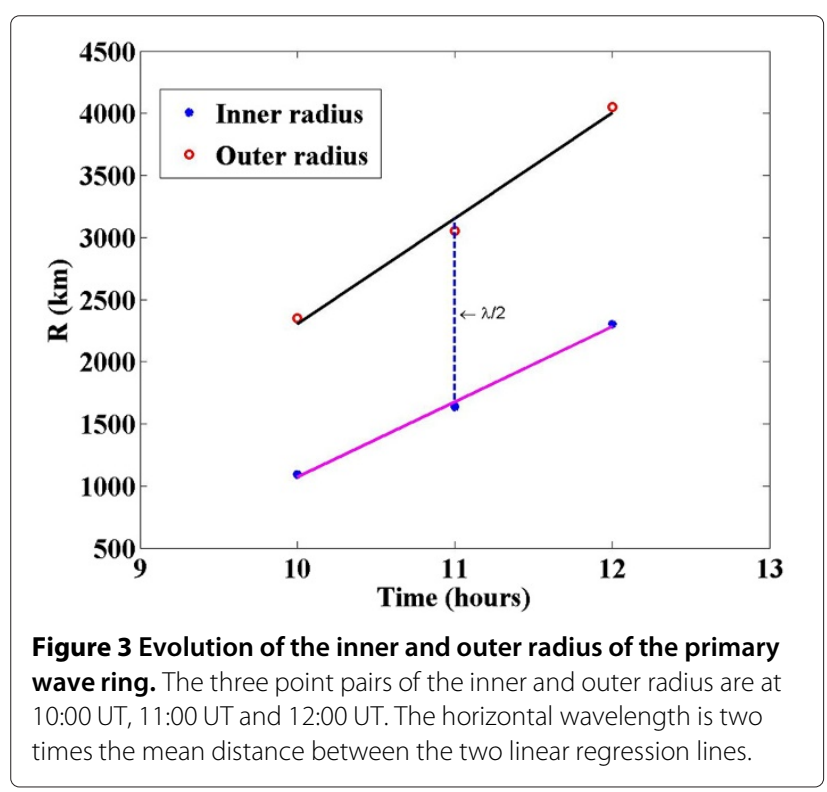


of sound. The wave characteristics are quite similar to those in the numerical simulation of Nicholls \& Pielke [5]. They interpreted the horizontally propagating circular wave outgoing from a thunderstorm region with the speed of sound as a Lamb wave mode $\mathrm{n} 1$ and $\mathrm{n} 2$. The $\mathrm{n} 1$ mode moved faster and resulted in deep subsidence warming, while the second mode propagated at half the speed and resulted in weak-low level uplift. The appearance of an uplift as a result of a thermally induced gravity wave is in accordance with our own results (Figure 2a). Parallel to Nicholls \& Pielke, the primary wave in our simulation is mostly soliton-like which might be interpreted as a shock wave front (as done by Nicholls \& Pielke). On the other hand large scale waves with speeds close to the speed of sound are often found in the thermosphere. They have periods of several hours and horizontal wavelengths of a few thousands kilometres. Gardner \& Shunk [6] as well as Vadas [25] classify these large-scale waves as atmospheric gravity waves.

In the case of our simulation, the surface colour change resulted in an increase in the fraction of solar radiation absorbed by the region. This resulted in an increase in the surface temperature and therefore in an increase in the temperature of the air located directly over the perturbed region. The observed buoyancy oscillation at $2 \mathrm{~km}$ altitude could be a result of either convective or radiative heating. The convective heating would be consistent with the evolution of the central perturbation, as the air seems to rise over the perturbation and then fall as the day progresses, with the opposite happening to the air around it (Figure 2).

\section{Secondary perturbations}

Surprisingly, two secondary perturbations (or secondary waves) appear in Figure 4. The first appears over Indonesia at 14:00 UT. The pathway between this perturbation and the source region, in the Sahara, is unclear because the primary wavefront has not arrived in Indonesia at the time the perturbation appears.

Later the wave front of the primary wave approaches Brazil at 15:00 UT (Figure 2c) and reaches its tropical convection zone at 16:00 UT (Figure 4a).

As the wave front comes in contact with the tropical convection zone, it scatters and a secondary wave is generated. The secondary wave is clearly visible as concentric wave rings outgoing from the center of the tropical convection zone $\left(10^{\circ} \mathrm{S}, 55^{\circ} \mathrm{W}\right)$. The vertical wind in the tropical convection zone also has a periodic oscillation which can be seen in Figure 4a. The outward propagation of the generated secondary wave can be seen in Figure 4a,b.

As can be seen in Figure 4c at 19:00 UT another wave front generated by the perturbation over the Sahara, scatters on the Brazilian tropical convection zone. Besides wave scattering based on the Huygens-Fresnel principle, we think that the latent heat release by periodic, vertical advection of moist air masses is another reason for the generation and amplification of a secondary wave over Brazil (Figure 4a,c).

The parameters of the secondary wave are estimated for the time interval between 19:00 UT and 23:00 UT. The wave parameters are derived in the same manner as for the primary wave. The point pairs of the inner and outer rings and their linear regression lines are shown in Figure 5. The estimated wave parameters are: $\langle\lambda\rangle=2600 \pm 600 \mathrm{~km}$, $\langle v\rangle=220 \pm 40 \mathrm{~m} / \mathrm{s},\langle p\rangle=3 \pm 1 \mathrm{~h}$.

In summary, the soil colour change induced a secondary circular large scale wave with a wave speed $\sim 70 \%$ of the speed of sound.

The generation of secondary waves from convectively generated gravity waves was simulated by Vadas [26], with the wave characteristics being quite similar to those in our simulation. The generation of secondary oceanic waves through interaction with the topography in a manner

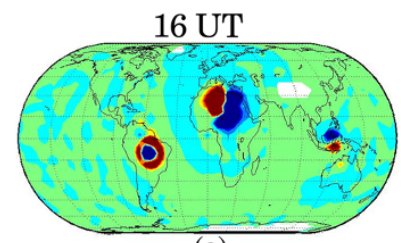

(a)

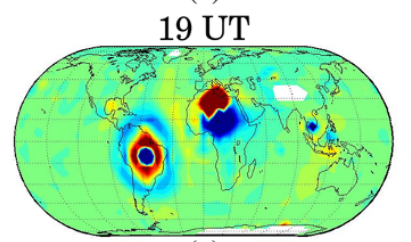

(c)

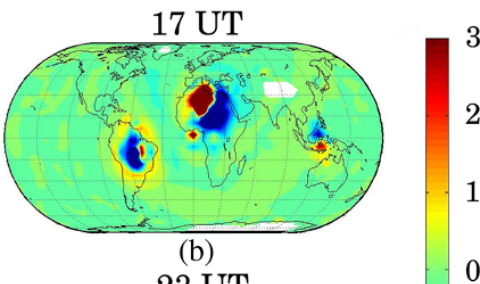

(b)

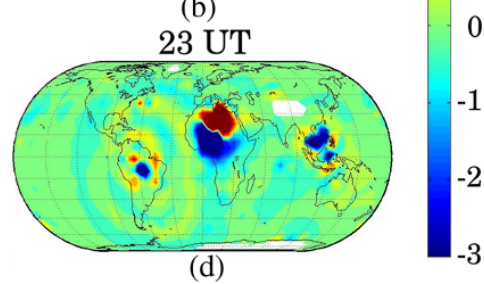

G

Figure 4 Evolution of the secondary wave above Brazil during day 1. The difference between the vertical wind at $2 \mathrm{~km}$ altitude of the perturbed run minus the control run is shown at (a) 16:00 UT, (b) 17:00 UT, (c) 19:00 UT, (d) 23:00 UT. 


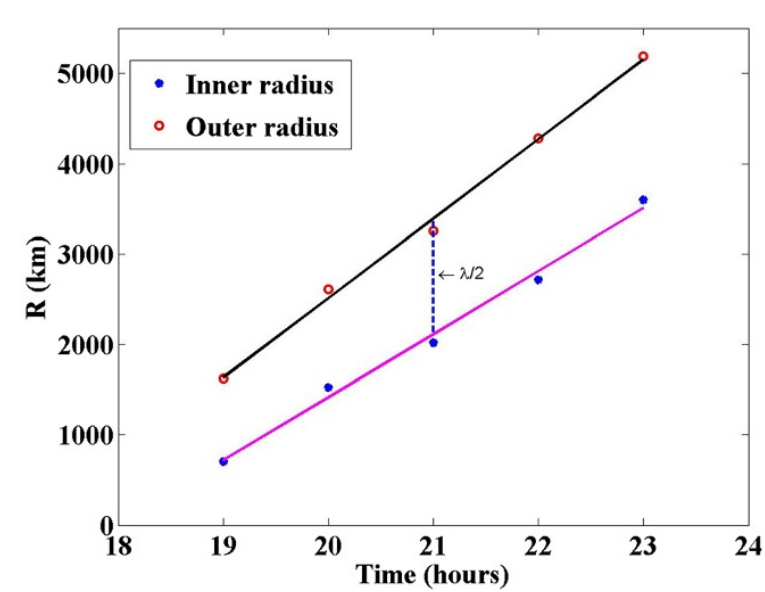

Figure 5 Evolution of the inner and outer radius of the secondary wave ring outgoing from Brazil. The five point pairs of the inner and outer radius are at 19:00 UT, 20:00 UT, 21:00 UT, 22:00 UT and 23:00 UT. The horizontal wavelength is two times the mean distance between the two linear regression lines.

similar to the interaction of our wave with the tropical convection zone, was reported by Vlasenko [27].

The scattering of the primary wave front results in a change in the vertical motion. Updrafts might produce condensation of moist air resulting in latent heat release which may further amplify the secondary wave. Indeed the strong amplitude of the secondary wave points to such an amplification process which would affect the precipitation rate and the regional climate.

An ensemble simulation was also performed, between 01.01.2000 and 01.06.2000, with a 5 day gap between each run. The main features (primary wave and excitation of secondary waves) are present in both the ensemble average and in each individual run. However the shape of the primary wave ring can differ indicating a seasonal variation in the azimuthal wave speeds, which is likely due to a seasonal variation of the mean flow and the thermal structure of the lower troposphere. For example, in June the southward propagation of the primary wave is enhanced compared to January. In March, a secondary wave is generated in the vicinity of Lake Victoria (Tanzania), where a tropical convention zone is present during that time of the year (rainy season) [28]. These examples show the potential of wave propagation studies with a realistic high-resolution climate model.

\section{Evolution five days later}

Five days after the initiation of the simulation, no circular wave patterns are visible. And while enhanced fluctuations are visible in the vicinity of the Sahara and the convective zones over Brazil and Indonesia, disturbances are also visible in a seemingly random distribution all over the globe. Furthermore the global mean standard deviation $\sigma$ linearly increases over the 5 days of our simulation from $\sigma=2 \cdot 10^{-4}$ on the first day to $\sigma=27 \cdot 10^{-4}$ on the fifth day. This indicates that the perturbed run diverges more and more from the control run with increase of time, making the attribution of cause and effect difficult. Our small perturbation analysis is only applicable for the first two days when the perturbation waves can be clearly separated from the random atmospheric waves. The coupling of the primary and secondary waves in our study could be exemplary to a similar coupling between migrating and non-migrating tides.

\section{Conclusions}

The soil colour change of a surface area in the eastern Sahara generates a traveling atmospheric disturbance. The advantage of our high-resolution climate model experiment is that we can study, for the first time, the generation and propagation of the TAD under realistic atmospheric conditions. This means that all the interactions between the TAD and the atmospheric jets, circulation cells, solar tides, planetary waves, random gravity waves, orography and tropical convection zones are included in the simulation. We find that the interaction of the TAD with the tropical convection zones over Brazil is most obvious.

The soil colour perturbation generates a primary atmospheric wave outgoing from the source region in the Sahara. It has an amplitude of $A>5 \sigma$, a mean horizontal wavelength of $\langle\lambda\rangle=3000 \pm 500 \mathrm{~km}$, a mean wave velocity of $\langle v\rangle=200 \pm 50 \mathrm{~m} / \mathrm{s}$ and a mean period of $\langle p\rangle=4 \pm 1 \mathrm{~h}$.

As the primary wave reaches Brazil, the wave front scatters at the tropical convection zone and generates secondary atmospheric outgoing waves. The latent heat release by moist air amplify the secondary wave to an amplitude of $A>5 \sigma$. The wave has a mean horizontal wavelength of $\langle\lambda\rangle=2600 \pm 600 \mathrm{~km}$, a mean wave velocity of $\langle v\rangle=220 \pm 40 \mathrm{~m} / \mathrm{s}$ and a mean period of $\langle p\rangle=3 \pm 1 \mathrm{~h}$.

In the present letter we only discussed the dynamical response of the global troposphere at $2 \mathrm{~km}$ height to the soil colour change in Sahara. This brief analysis of the numerical experiment already gave new results on the land-atmosphere interaction, global teleconnections and wave dynamics. We expect that a future analysis of the simulation data at different altitudes will provide us with a better understanding of how regional soil colour changes affect the atmospheric layers above. For example how much energy and momentum are transported by wave coupling and radiative transfer, which wave modes are most important and which role do the soil colour changes play on the generation of non-migrating atmospheric tides.

Another topic would be the investigation of the dependences of the primary and secondary TAD parameters on 
the location, size and strength of the sources. Such studies are relevant for geoengineering as well as for understanding of the climate processes and wave-wave interactions.

\section{Abbreviations}

ATM: Atmospheric geophysical model; CESM: Community earth system model; CICE: Sea - ice data model; CLM: Community land model; CPL: Coupler to CESM; GLC: Land-ice geophysical model in CESM; ICE: Sea-ice geophysical model in CESM; docn: prescribed data ocean model; LND: Land geophysical model in CESM; MODIS: Moderate-resolution imaging spectroradiometer; OCN: Ocean geophysical model in CESM; TAD: Traveling atmospheric disturbance; WACCM: Whole atmosphere community climate model; NOAA National oceanic and atmospheric administration.

\section{Competing interests}

The authors declare that they have no competing interests.

\section{Authors' contributions}

EP performed the simulations and data analysis. $\mathrm{KH}$ contributed to the data analysis and interpretation. Both authors read and approved the final manuscript.

\section{Acknowledgements}

We would like to thank the Center for Space and Habitability (University of Bern) for the PhD fellowship that made this study possible. We would like to thank the WACCM forum for the invaluable information it provided. We would also like to thank Dominik Scheiben and Ansgar Schanz for the computer technical support they provided. Finally we would like to thank Niklaus Kämpfer, Peter Wurz, Helmut Lammer, and Raymond Pierrehumbert for the valuable discussions and advises.

\section{Author details}

${ }^{1}$ Institute of Applied Physics, University of Bern, Sidlerstrasse 5, Bern, Switzerland. ${ }^{2}$ Center for Space and Habitability, University of Bern, Bern, Switzerland. ${ }^{3}$ Oeschger Centre for Climate Change Research, University of Bern, Bern, Switzerland.

\section{Received: 28 February 2014 Accepted: 5 August 2014}

Published online: 31 August 2014

\section{References}

1. Held IM (2005) The gap between simulation and understanding in climate modeling. Bull Am Meteorological Soc 86:1609-1614

2. Alexander MJ, Geller M, McLandress C, Polavarapu S, Preusse P, Sassi F, Sato K, Eckermann S, Ern M, Hertzog A, Kawatani Y, Pulido M, Shaw TA, Sigmond M, Vincent R, Watanabe S (2010) Recent developments in gravity-wave effects in climate models and the global distribution of gravity-wave momentum flux from observations and models. Q J R Meteorological Soc 136:1103-1124

3. Walland DJ, Simmonds I (1996) Modelled atmospheric response to changes in Northern Hemisphere snow cover. Climate Dyn 13:25-34

4. Kirschbaum MUF, Whitehead D, Dean SM, Beets PN, Shepherd JD, Ausseil A-GE (2011) Implications of albedo changes following afforestation on the benefits of forests as carbon sinks. Biogeosciences 8:3687-3696

5. Nicholls ME, Pielke RA (2000) Thermally induced compression waves and gravity waves generated by convective storms. J Atmos Sci 57:3251-3271

6. Gardner LC, Schunk RW (2010) Generation of traveling atmospheric disturbances during pulsating geomagnetic storms. J Geophys Res: Space Phys 115:2156-2202

7. Seitz R (2013) Knowing the uknowns. Earth's Future doi:10.1002/2013EF000151

8. Held IM, Suarez MJ (1974) Simple albedo feedback models of the icecaps. Tellus 26:613-629

9. Betts RA (2000) Offset of the potential carbon sink from boreal forestation by decreases in surface albedo. Nature 408:187-190

10. Ridgwell A, Singarayer JS, Hetherington AM, Valdes PJ (2007) Tackling regional climate change by leaf Albedo bio-geoengineering. Curr Biol 19:146-150
11. Vertenstein M, Craig T, Middleton A, Feddema D, Fisher C (2012) CESM 1.0.4 user's guide. Available from: http://www.cesm.ucar.edu/models/ cesm1.0/cesm/cesm_doc_1_0_4/book1.html

12. Neale RB, Gettelman A, Park S, Chen C, Lauritzen PH, Williamson DK, Conley AJ, Kinnison D, Marsh D, Smith AK, Vitt F, Garcia R, Lamarque JF, Mills M, Tilmes S, Morrison H, Cameron-Smith W, Collins WD, lacono MT, Easter RC, Liu X, Ghan SJ, Rasch PJ, Taylor MA (2012). Description of the NCAR Community Atmosphere Model (CAM 5.0). http://www.cesm.ucar. edu/models/cesm1.0/cam/docs/description/cam5_desc.pdf

13. Pedatella NM, Fuller-Rowell $T$, Wang $H$, Jin $H$, Miyoshi $Y$, Fujiwara $H$, Shinagawa H, Liu H-L, Sassi F, Schmidt H, Matthias V, Goncharenko L (2014) The neutral dynamics during the 2009 sudden stratosphere warming simulated by different whole atmosphere models. J Geophys Res: Space Phys. http://dx.doi.org/10.1002/2013JA019421

14. Pedatella NM, Liu H-L (2013) Influence of the El Niño southern oscillation on the middle and upper atmosphere. J Geophys Res: Space Phys 118:2744-2755. http://dx.doi.org/10.1002/2013JA019421

15. Lu X, Liu H-L, Liu AZ, Yue J, Mclnerney JM, Li Z (2012) Momentum budget of the migrating diurnal tide in the whole atmosphere community climate model at vernal equinox. J Geophys Res: Atmos 17. http://dx.doi. org/10.1002/2013JA019421

16. Tan B, Chu X, Liu H-L, Yamashita C, Russell JM (2012) Atmospheric semidiurnal lunar tide climatology simulated by the whole atmosphere community climate model. J Geophys Res 117:1-11. doi:10.1029/2012JA017792

17. Tan B, Chu X, Liu H-L, Yamashita C, Russell JM (2012) Zonal-mean global teleconnection from 15 to $110 \mathrm{~km}$ derived from SABER and waccm. J Geophys Res: Atmos 117:1-11. doi:10.1029/2011JD016750

18. Tan B, Chu X, Liu H-L, Yamashita C, Russell JM (2012) Parameterization of the inertial gravity waves and generation of the quasi-biennial oscillation. J Geophys Res: Atmos 117. doi:10.1029/2011JD016778

19. Davis RN, Du J, Smith AK, Ward WE, Mitchell NJ (2013) The diurnal and semidiurnal tides over Ascension Island $\left({ }^{\circ} \mathrm{S}, 14^{\circ} \mathrm{W}\right)$ and their interaction with the stratospheric quasi-biennial oscillation: studies with meteor radar, eCMAM and waccm. Atmos Chem Phys 13(18):9543-9564

20. Smith KL, Polvani LM, Marsh DR (2012) Mitigation of 21st century Antarctic sea ice loss by stratospheric ozone recovery. Geophys Res Lett 39(20):L20701

21. Holton JR, Hakim GJ (2013) An introduction to dynamic meteorology. Academic Press, Waltham, MA 02451, USA, p 552

22. National Oceanic and Atmospheric Administration's Space Environment Center. www.sec.noaa.gov

23. Oleson KW, Lawrence DM, Bonan GB, Flanner MG, Kluzek E, Lawrence PJ Levis S, Swenson SC, Thornton PE, Dai A, Decker M, Dickinson R, Feddema J, Heald CL, Hoffman F, Lamarque J, Mahowald N, Niu G, Qian T, Randerson J, Tunning S, Sakaguchi K, Slater A, Stockli R, Wang A, Yang Z, Zeng X, Zeng X (2010) Technical description of version 4.0 of the community land model (CLM). NCAR/TN-478+STR. doi:10.5065/D6FB50WZ. http://nldr.library.ucar.edu/repository/assets/ technotes/TECH-NOTE-000-000-000-848.pdf

24. Moderate-resolution Imaging Spectroradiometer NASA Webpage. http:// modis.gsfc.nasa.gov/

25. Vadas SL, Liu H-L (2013) Numerical modelling of the large-scale neutral and plasma responses to the body forces created by the dissipation of gravity waves from 6 h of deep convection in Brazil. J Geophys Res: Space Phys 118:2593-2617. http://www.cora.nwra.com/ vasha/VadasLiu_JGR_ 2013.pdf

26. Vadas SL, Liu H-L (2009) Generation of large-scale gravity waves and neutral winds in the thermosphere from the dissipation of convectively generated gravity waves. J Geophys Res 114:A10310

27. Vasiliy V (2005) Generation of secondary internal waves by the interaction of an internal solitary wave with an underwater bank. J Geophys Res 110. doi:10.1029/2004JC002467

28. Kizzan M, Rodhe A, Xu C-Y, Ntale HK, Halldin S (2009) Temporal rainfall variability in the Lake Victoria Basin in East Africa during the twentieth century. Theor Appl Climatol 98:119-135. doi:10.1007/s00704-008-0093-6

doi:10.1186/s40562-014-0013-9

Cite this article as: Proedrou and Hocke: A traveling atmospheric disturbance generated by a soil colour change in a high-resolution climate model experiment. Geoscience Letters 2014 1:13. 